\title{
Analysis on Synthesis of Silica Nanoparticles and its Effect on Growth of T. Harzianum \& Rhizoctonia Species
}

\author{
Jaya Verma* and Arpita Bhattacharya \\ Amity Institute of Nanotechnology, Amity University, India

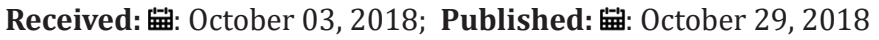 \\ *Corresponding author: Jaya Verma, Amity Institute of Nanotechnology, Amity University, India
}

\begin{abstract}
Silica nanoparticles have been prepared by sol-gel method and peptization process. The silica nanoparticles were obtained by hydrolysis of tetraethyl-orthosilicate (TEOS) in ethanol but variation in parameters improved particles size from $290 \mathrm{~nm}$ to $85 \mathrm{~nm}$ in sol-gel process and $190 \mathrm{~nm}$ by peptization process using nitric acid as electrolyte. Detailed study on these nanoparticles was done by characterizing nanoparticles using dynamic light scattering. Scanning electron microscopy, X-ray diffraction, FTIR analysis and UV-visible spectrophotometer. Antifungal effect of prepared nano silica was carried out in Potato dextrose agar (PDA) media using concentration of nanoparticle at $1 \mathrm{wt} \%$ against trichoderma harzianum and rhizoctonia solani.
\end{abstract}

Keywords: Silica nanoparticles; Temperature; TEOS; DLS; Trichoderma harzianum; Rhizoctonia solani

\section{Introduction}

Nanoparticles with size ranging between objects and microparticles have attracted much attention. These particles with various specialized functions not only deepen our understanding of nature but also serve the basic for development of new advance technology. Nanoparticles are characterized by size-dependent properties both size and surface effects are important. By controlling these, it is possible in principle to design materials of required optical, magnetic, elastic, chemical etc. properties. There is increasing interest in the design and synthesis of topological structures composed of monocrystals of various size and shapes [1]. The sol-gel methods are the most general method of synthesis of silica nanoparticles. Appetence in the sol-gel processing of ceramic and glass materials started in the half of 1800s by Ebelman and Graham's researches on silica gels [2]. The sol-gel technique is in expensive and the silica gels manufactured are non-poisonous matters [3-8]. Stober supplied monodisperse and nonporous silica spheres with the hydrolysis of tetraethyl orthosilicate (TEOS) in strongly basic medium. Stober and Fink promoted chemical reactions which checked up the growth of spherical silica particles [9]. Bogush and Zukoski procure monodispersed silica particles with controlled hydrolysis of TEOS in ethanol [10]. Sung Kyoo Park provided silica nanoparticles from TEOS in ethanol in order that controlled particle properties using a semi-batch process [11]. Ryu had prepared amorphous silica by oxidation of silicon [12-13].

In the present work, we suggested a novel method for preparing amorphous silica nanoparticles through the sol-gel techniques at various temperature range from $78^{\circ} \mathrm{C}$ to $650^{\circ} \mathrm{C}$ to obtain best particle size even we prepared silica nanoparticles through peptization process also, using electrolyte nitric acid / hydrochloric acid / sulfuric acid for comparative study on particle size analysis to obtain best particle size below $100 \mathrm{~nm}$. Another study on performed for fungal effect on human body. Fungi are heterotrophic organisms which are able to reproduce sexually as well as asexually. About 100 infectious fungal agents have been detected in man. The mycoses or fungal infection can be of various forms as:

a) Superficial-seen on the skin, the hair, and nails.

b) Subcutaneous-infection reaching dermis or subcutaneous tissue

c) Systemic-internal organs infected deeply

d) Opportunistic-infection in immunocompromised patients

Several works have been highlighted very high bactericidal efficiency on different microorganisms but there is no detail explanation for antifungal testing with silica nanoparticles against fungus that causing human disease. In this study, the effect of silica nanoparticle was observed against Trichoderma Harzianum and Rhizoctonia Solani.

\section{Trichoderma Harzianum}

Morphology: Colonies were originally hyaline darkening to white with green tufts in most species. The form was irregular which rapidly grew and merged forming green carpet like appearance. 
The conidiophores were branched and hyaline. Phialides were divergent and flask-shaped. Conidia were generally green, smooth or roughened, ranged in shape from globose to ellipsoidal, and were produced in slimy heads Conidiophores were highly branched and demonstrated a pyramidal arrangement.

Pathogenecity: Trichoderma harzianum infections are opportunistic and develop in immunocompromised patients, such as neutropenic cases and transplant recipients, as well as patients with chronic renal failure, chronic lung disease, or amyloidosis. Peritonitis, pulmonary, perihepatic, and disseminated infections have so far been reported. A disseminated fungal infection was detected in the postmortem examination of a renal transplant recipient and confirmed in culture. The only other reported infection by this fungus caused peritonitis in a diabetic patient. Trichoderma harzianum were identified as causative agents of opportunistic fungal infections with increasing frequency. Trichoderma harzianum isolates are reported predominantly to cause health problems in humans ranging from localized infections to fatal disseminated diseases. Thus, it is very necessary to delete the negative pathogenic aspects of fungi by using proper treatment and care [14].

\section{Rhizoctonia Solani}

Human infections caused by Rhizoctonia are very rare, and first case report of keratitis by Rhizactonia was reported way back in 1977 [15]. Rhizoctonia solani is a most widely recognized strong saprophyte with a great diversity of host plants. It is a first ever case of extensive human mycosis caused by Rhizoctonia solani in a 65-year-old diabetic and hypertensive farmer, with a history of head injury caused by fall of mud wall. Necrotic material collected revealed septate fungal hyphae with bacterial co-infection and after mycological study \& diagnosis it was confirmed the presence of rhizoctonia solani [16]. So, in this paper we tested anti-fungal effect of silica nanoparticles against these two fungi i.e. trichoderma harzianum and rhizoctonia solani in PDA media.

\section{Experimental}

\section{Materials}

Tetraethyl orthosilicate (TEOS) were purchased from Sigma Aldrich Chemicals Pvt Limited (India). Ethanol from Fischer Scientific (India), and Ammonium hydroxide from Qualikems Fine Chemical Pvt. Ltd. (India) was purchased. Potato dextrose agar (PDA) was purchased from HiMedia Laboratories Pvt Limited (India). Instruments-UV 1800 Shimadzu UV spectrophotometer, Malvern instruments-Zetasizer Nano S-90, Shimadzu 8400 spectrophotometer and Bruker D8 Focus X-Ray Diffractometer, Bruker Universal materials tester (CETR UMT-3) SEM-Zeiss microscopy.

\section{Methods}

\section{Synthesis of Silica Nanoparticles through Sol-Gel Method}

Silica nanoparticles were prepared according to the wellknown Stöber method by hydrolysis and condensation of tetraethyl-orthosilicate. $8 \mathrm{ml}$ of TEOS was added in a mixture of $100 \mathrm{ml}$ ethanol with $35 \mathrm{ml}$ of DI water. This solution was stirred for 40 minutes and $\mathrm{pH}$ was maintained at 10 by adding ammonium hydroxide drop-wise. The synthesis starts with mixing and stirring of the components, requires a reaction time of about $2 \mathrm{hr}$ and is finished by centrifugation at $8000 \mathrm{rpm}$ for 5-10 minutes and overnight of drying at temperatures at $100^{\circ} \mathrm{C}$ and calcinated at $650^{\circ} \mathrm{C}$ for 2 hours. Same process was used to obtain best particle size value of silica nanoparticle by changing in different parameters like temperature $\left(78^{\circ} \mathrm{C}, 100^{\circ} \mathrm{C}, 650^{\circ} \mathrm{C}\right)$ and TEOS $(4 \mathrm{ml}, 8 \mathrm{ml}, 16 \mathrm{ml})$ concentration.

\section{Synthesis of Silica Nanoparticles through Peptization Process}

In a typical peptization process, a specific amount of TEOS (8 $\mathrm{mL}$ ) was added to $100 \mathrm{ml}$ of ethanol and $35 \mathrm{ml}$ of DI water under continuous stirring. After 20 minutes electrolyte i.e., nitric acid or hydrochloric acid or sulfuric acid was added to this solution and obtained silica gel containing salt. This silica gel was washed with DI water to remove salt and obtain a silica wet gel. After that DI water and $\mathrm{NaOH}$ was added to maintain $\mathrm{pH}$ at 10 . Silica gel was formed, then heated for overnight at $150^{\circ} \mathrm{C}$.

\section{Antifungal Testing}

Dissolved $39 \mathrm{gm}$ of PDA in $1000 \mathrm{ml}$ distilled water. Under stirring this solution was sterilized by autoclaving at 15 psi at $121^{\circ} \mathrm{C}$ for 15 minutes. Nanoparticles concentration was maintained in the media at $1 \%$. Cooled it to room temperature prior to dispense. The fungi were inoculated on separate petriplates containing sterilized media with $1 \mathrm{wt} \%$ of nanoparticles. After this placed these petriplates in BOD (Biochemical oxygen demand) chamber. Growth of fungus was observed for 7-10 days.

\section{Characterization}

Prepared nanoparticles were suspended in water and particle size was measured by Dynamic Light Scattering using Malvern instruments (Zetasizer Nano S-90). Fourier transform infrared spectroscopy of all prepared nanoparticles was performed with Shimadzu 8400 Spectro-photometer in powder form. X-Ray Diffraction was carried out ofall nanoparticles using Bruker D8 Focus in powder form. UV visible spectrum of prepared nanoparticles have been reported by UV 1800 Shimadzu UV spectrophotometer suspensions form prepared in water and SEM was performed using Zeiss scanning electron microscope in powder form. Antifungal effect was observed in PDA (potato dextrose agar) media.

\section{Results and Discussion}

Particle size measurement was carried out through dynamic light scattering. Particle size of prepared silica nanoparticles through sol-gel method was observed as mentioned in Table 1 and particle size of prepared silica nanoparticles through peptization process by using different electrolyte like nitric acid or $\mathrm{HCl}$ or $\mathrm{H}_{2}$ $\mathrm{SO}_{4}$ is mentioned in Table 2. Particle size of nano silica at different concentration of precursor and at different temperature up to $650^{\circ} \mathrm{C}$ was measured. To obtain particle size below $100 \mathrm{~nm}$ silica nanoparticle was prepared through two different process- sol gel and peptization process. Through sol-gel process particle size of nano silica was observed $154 \mathrm{~nm}$ at $650^{\circ} \mathrm{C}$ by $8 \mathrm{ml}$ of TEOS that is minimum particle size as compared to $78^{\circ} \mathrm{C}$ and $100^{\circ} \mathrm{C}$ because 
at higher temperature gel structure breaks. After that we changed

concentration of TEOS twice means $16 \mathrm{ml}$ observed the particle the concentration of TEOS, firstly reduced by $1 / 2$ ( $4 \mathrm{ml}$ of TEOS), size was $85 \mathrm{~nm}$ at $650^{\circ} \mathrm{C}$.

obtained particle size was $260 \mathrm{~nm}$ at $650^{\circ} \mathrm{C}$.After increasing the

Table 1: Particle size analysis of nano-silica prepared through sol-gel process.

\begin{tabular}{|c|c|c|}
\hline TEOS concentration & Temperature & Nano-Silica particle size \\
\hline $4 \mathrm{ml}$ & $78^{\circ} \mathrm{C}$ & $290 \mathrm{~nm}$ \\
\hline $4 \mathrm{ml}$ & $100^{\circ} \mathrm{C}$ & $260 \mathrm{~nm}$ \\
\hline $4 \mathrm{ml}$ & $650^{\circ} \mathrm{C}$ & $203 \mathrm{~nm}$ \\
\hline $8 \mathrm{ml}$ & $78^{\circ} \mathrm{C}$ & $175 \mathrm{~nm}$ \\
\hline $8 \mathrm{ml}$ & $100^{\circ} \mathrm{C}$ & $154 \mathrm{~nm}$ \\
\hline $8 \mathrm{ml}$ & $650^{\circ} \mathrm{C}$ & $149 \mathrm{~nm}$ \\
\hline $16 \mathrm{ml}$ & $78^{\circ} \mathrm{C}$ & $105 \mathrm{~nm}$ \\
\hline $16 \mathrm{ml}$ & $100^{\circ} \mathrm{C}$ & $85 \mathrm{~nm}$ \\
\hline $16 \mathrm{ml}$ & $650^{\circ} \mathrm{C}$ & 2 \\
\hline
\end{tabular}

Table 2: Particle size analysis of nano-silica prepared through peptization process.

\begin{tabular}{|c|c|}
\hline Acid & Particle size \\
\hline Nitric acid & $190 \mathrm{~nm}$ \\
\hline Hydrochloric acid & $310 \mathrm{~nm}$ \\
\hline Sulfuric acid & $277 \mathrm{~nm}$ \\
\hline
\end{tabular}

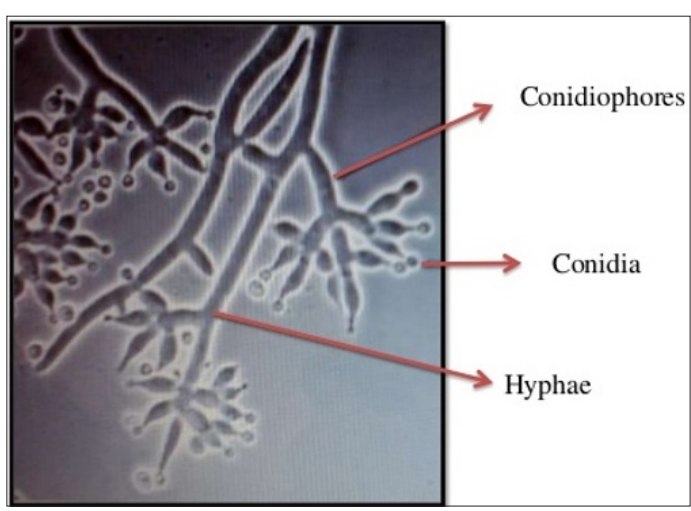

Figure 1: Morphological structure of Trichoderma.

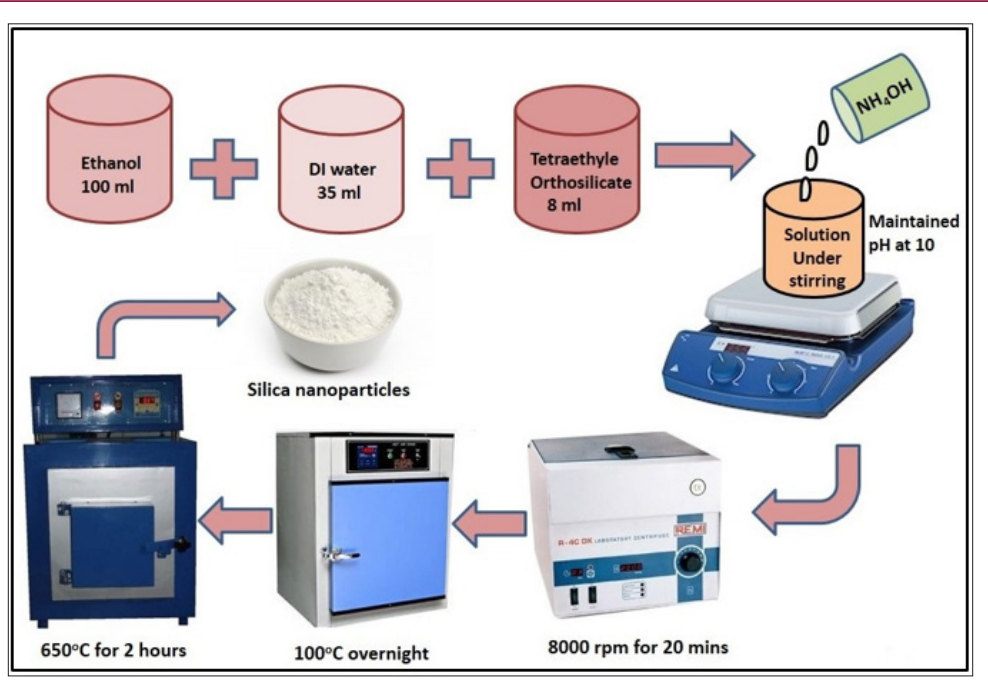

Figure 2: Synthesis procedure of silica nanoparticle through sol-gel process. 
Even silica nanoparticle was prepared through peptization process but obtained particle size was $190 \mathrm{~nm}, 310 \mathrm{~nm}$ and $277 \mathrm{~nm}$ using electrolyte nitric acid, $\mathrm{HCl}$ and $\mathrm{H}_{2} \mathrm{SO}_{4^{*}}$ (Figures 1-7) So further for all characterization were proceed with silica nanoparticle prepared through $16 \mathrm{ml}$ of TEOS due to smaller particle size and this particle size shows better anti-fungal effect as compared to others. XRD analysis was performed for silica nanoparticle prepared through $16 \mathrm{ml}$ of TEOS at temperature $78^{\circ} \mathrm{C}, 100^{\circ} \mathrm{C}$ and $650^{\circ} \mathrm{C}$. The $\mathrm{X}$-ray powder diffraction pattern of the nanoparticles were recorded using $\mathrm{CuK} \alpha(1.5406 \AA)$ radiation at room temperature in the range 20 to $80^{\circ}$ in $2 \theta$ scale. Amorphous nature of silica nanoparticle was confirmed by broad peak in XRD analysis at $2 \theta=15^{\circ}(\mathrm{hkl}=100)$ but XRD peak at $650^{\circ} \mathrm{C}$ was best as compared to $78^{\circ} \mathrm{C}$ and $100^{\circ} \mathrm{C}$ as shown in Figures 8 \& 9 .

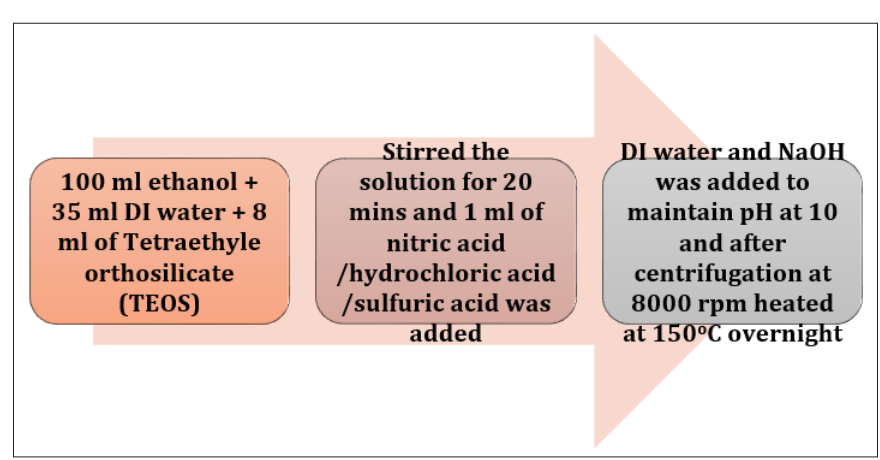

Figure 3: Synthesis procedure of silica nanoparticle through peptization process.

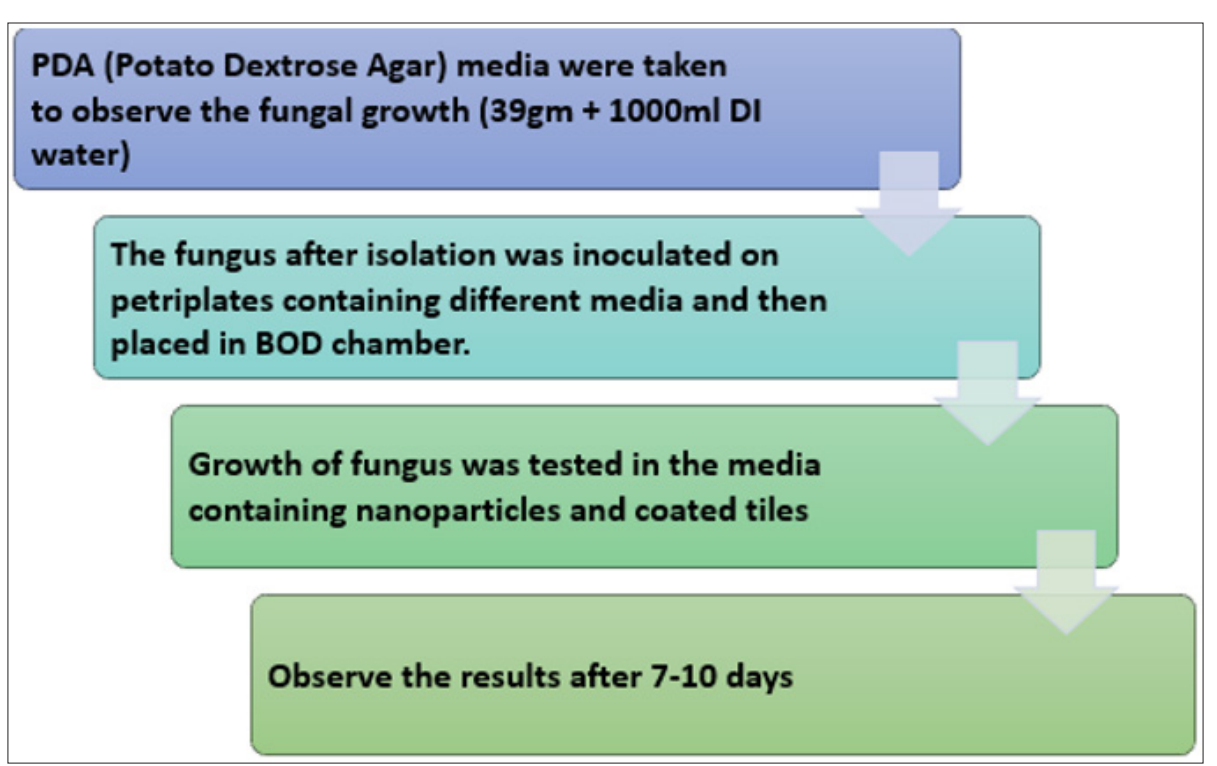

Figure 4: Flow chart for antifungal testing.

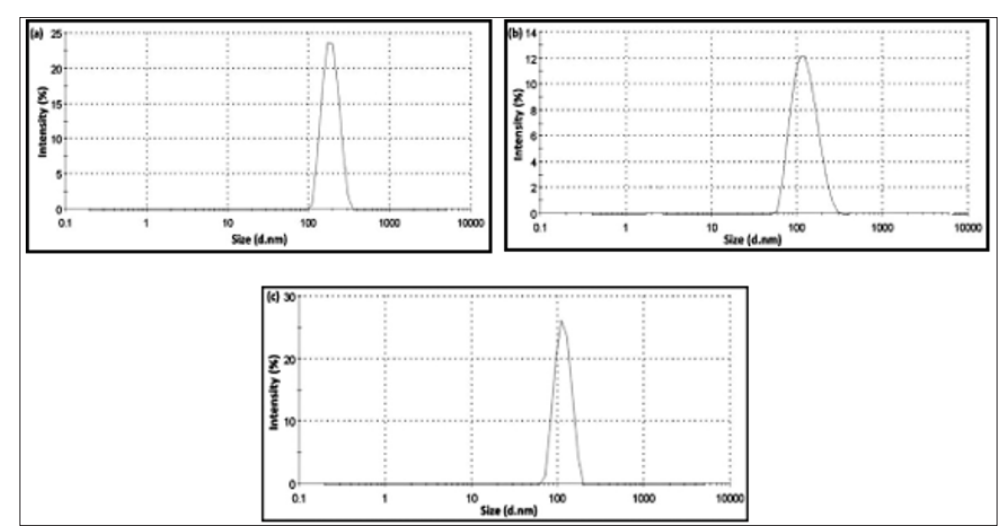

Figure 5: Particle size analysis of silica nanoparticles prepared through sol-gel method by $4 \mathrm{ml}$ of TEOS at temperature $(\mathrm{a}) 78^{\circ} \mathrm{C}$ (b) $100^{\circ} \mathrm{C}$ (c) $650^{\circ} \mathrm{C}$. 

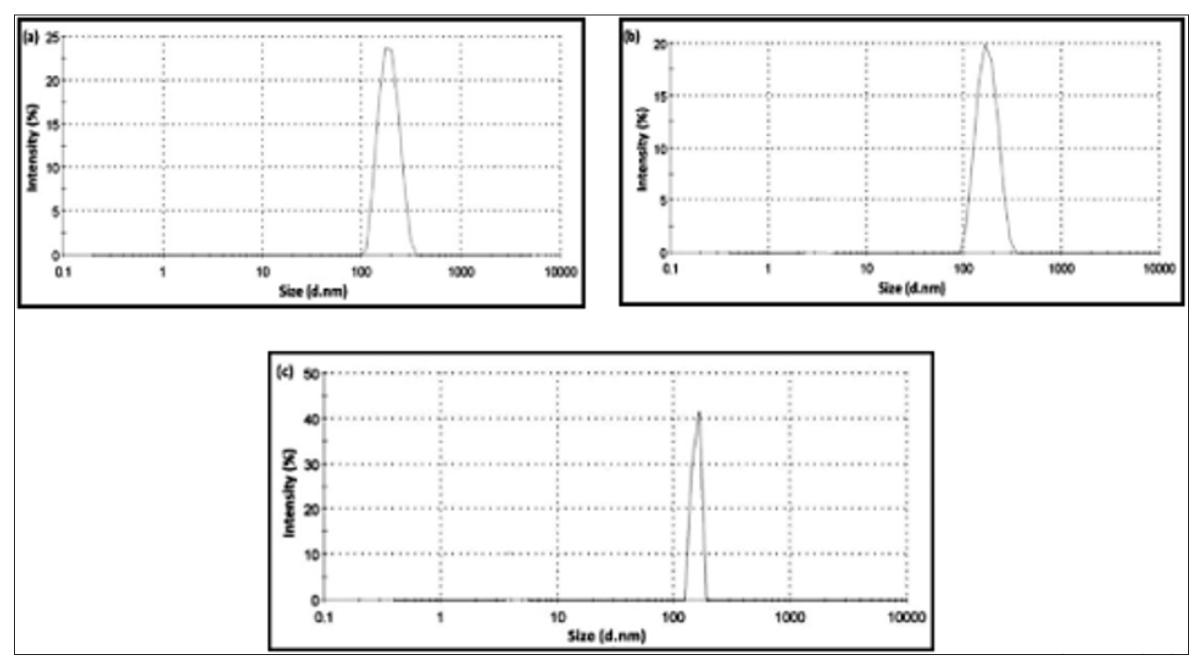

Figure 6: Particle size analysis of silica nanoparticles prepared through sol-gel method by $8 \mathrm{ml}$ of TEOS at temperature (a) $78^{\circ} \mathrm{C}$ (b) $100^{\circ} \mathrm{C}$ (c) $650^{\circ} \mathrm{C}$
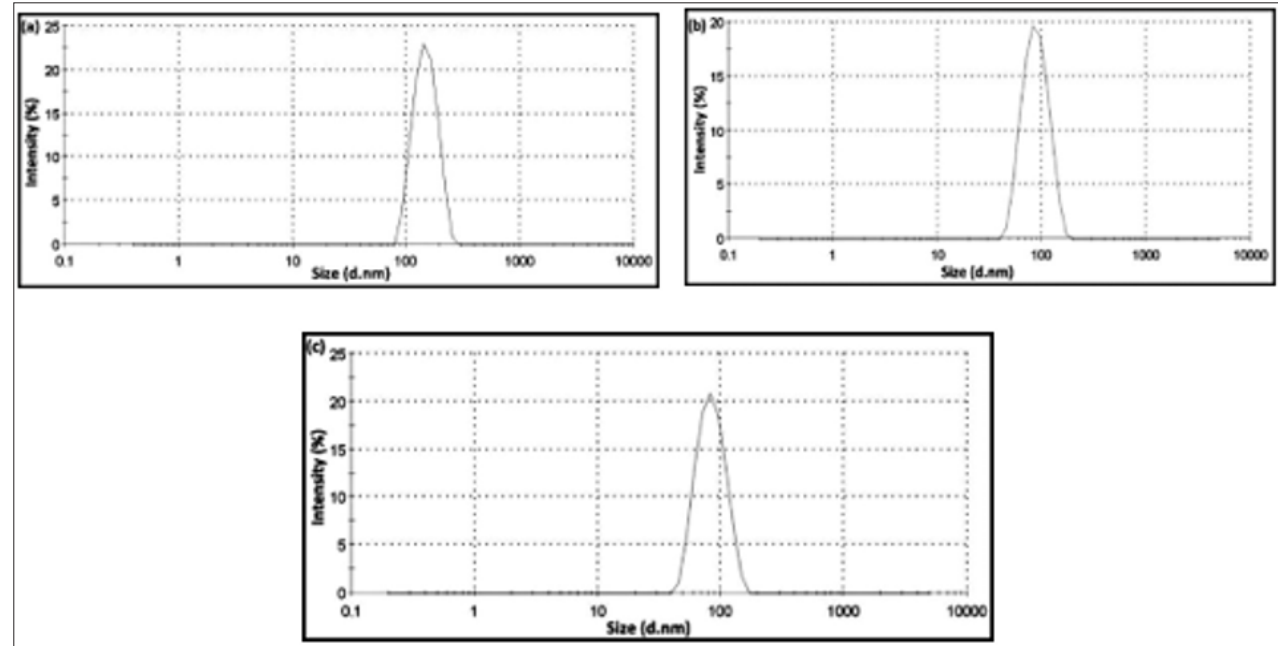

Figure 7: Particle size analysis of silica nanoparticles prepared through sol-gel method by $16 \mathrm{ml}$ of TEOS at temperature (a) $78^{\circ} \mathrm{C}$ (b) $100^{\circ} \mathrm{C}$ (c) $650^{\circ} \mathrm{C}$.
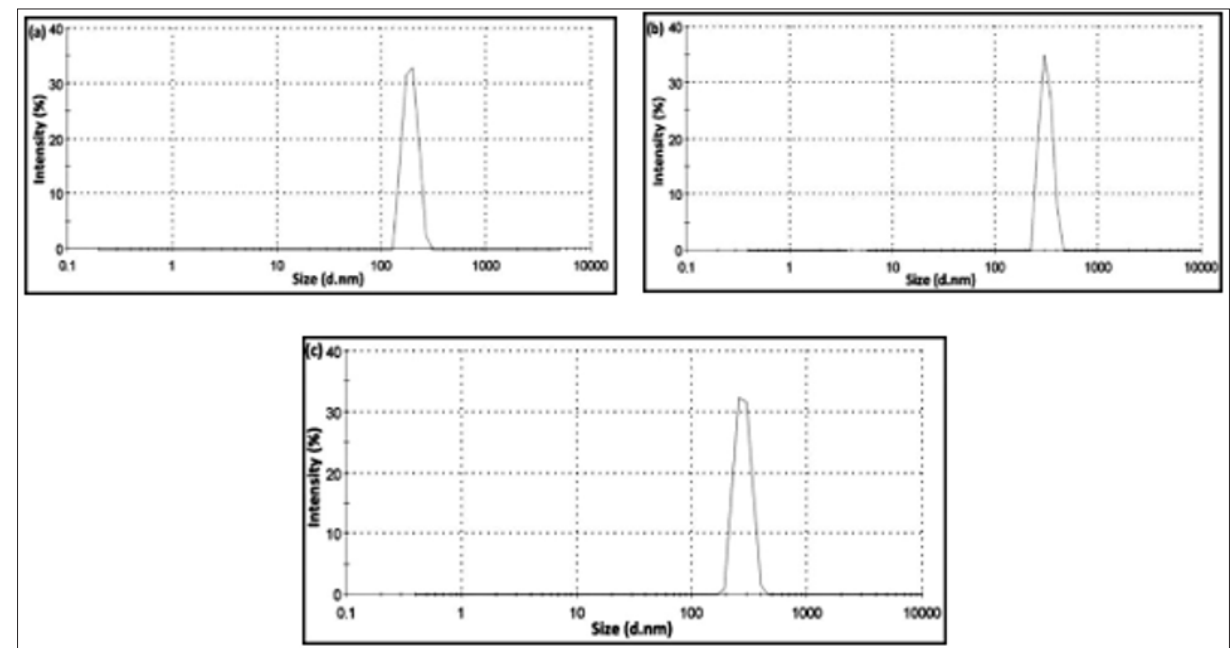

Figure 8: Particle size analysis of silica nanoparticles prepared through peptization process using (a) Nitric acid (b) Hydrochloric acid (c) Sulfuric acid. 

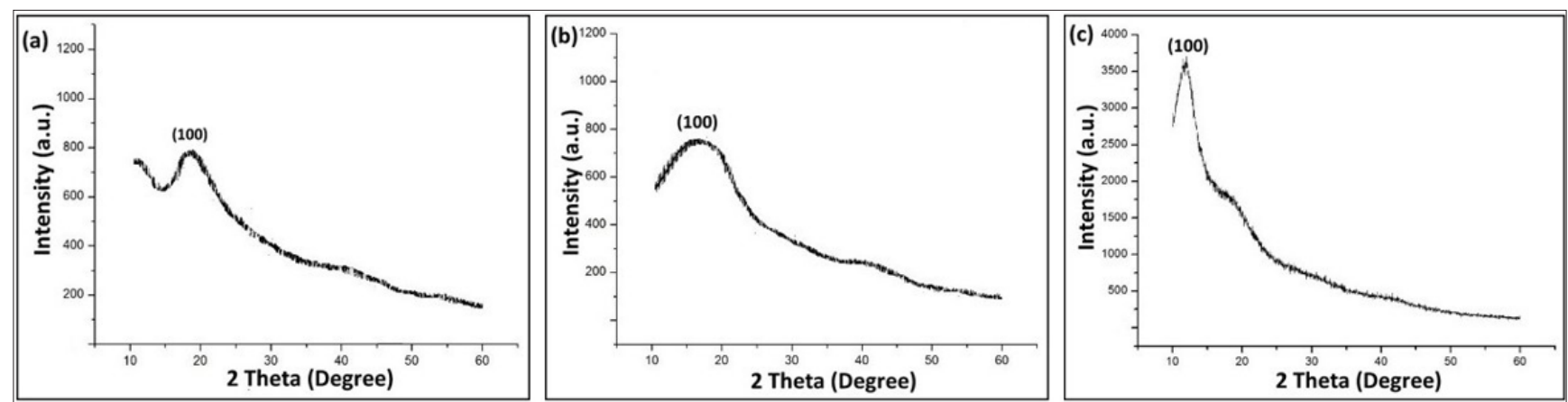

Figure 9: XRD analysis of silica nanoparticles prepared through sol-gel method by $16 \mathrm{ml}$ of TEOS at temperature $(\mathrm{a}) 78^{\circ} \mathrm{C}(\mathrm{b})$ $100^{\circ} \mathrm{C}$ (c) $650^{\circ} \mathrm{C}$.

In SEM image of silica nanoparticle have shown prepared by $16 \mathrm{ml}$ of TEOS at $650^{\circ} \mathrm{C}$. Scanning electron microscopy shows the spherical shape of silica nanoparticles. UV visible analysis was carried out in the region of 200-700 nm prepared by $16 \mathrm{ml}$ of TEOS at $650^{\circ} \mathrm{C}$ and obtained absorption peak $\lambda_{\max }$ at $270 \mathrm{~nm}$ as shown in Figures $10 \& 11$. In FTIR analysis, shows the FTIR spectra of silica nanoparticles prepared through sol-gel process using 16 $\mathrm{ml}$ of precursor at $650^{\circ} \mathrm{C}$. In the spectra of silica, the band around $1070 \mathrm{~cm}^{-1}$ corresponds to assymetric stretching vibration of Si-O-Si bond whereas $3300 \mathrm{~cm}^{-1}$ and $1640 \mathrm{~cm}^{-1}$ bands have appeared for $\mathrm{H}-\mathrm{O}-\mathrm{H}$ stretching and bending of absorbed water. Another peak at around $910 \mathrm{~cm}^{-1}$ corresponds to Si-OH bond. Antifungal testing of silica nanoparticle was carried out in potato dextrose media against fungus- trichoderma harzianum and rhizoctonia solani as shown in the Figures $12 \& 13$. The presence of silica nanoparticle (1wt $\%$ ) reduced the growth of T. harzianum up to $80 \%$ as shown in Figure 13(ii). And growth reduction was observed up-to $70 \%$ in Rhizoctonia solani as shown in Figure 14.

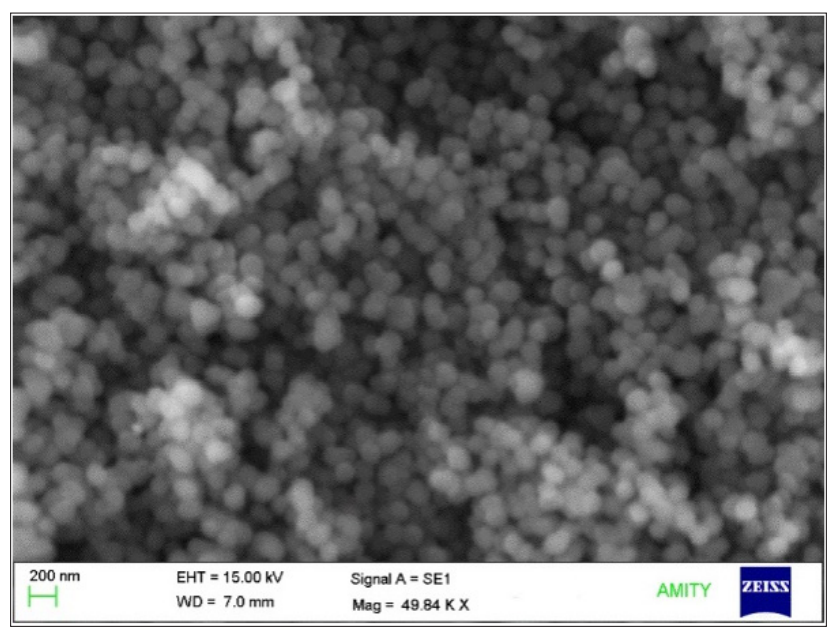

Figure 10: $\mathrm{SEM}$ image of $\mathrm{SiO}_{2}$ nanoparticle.

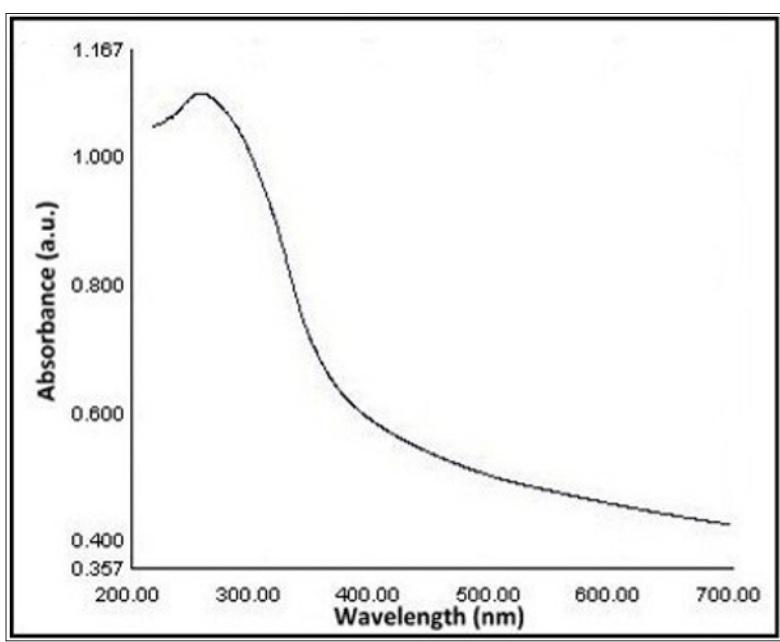

Figure 11: UV visible spectrum of silica nanoparticles. 


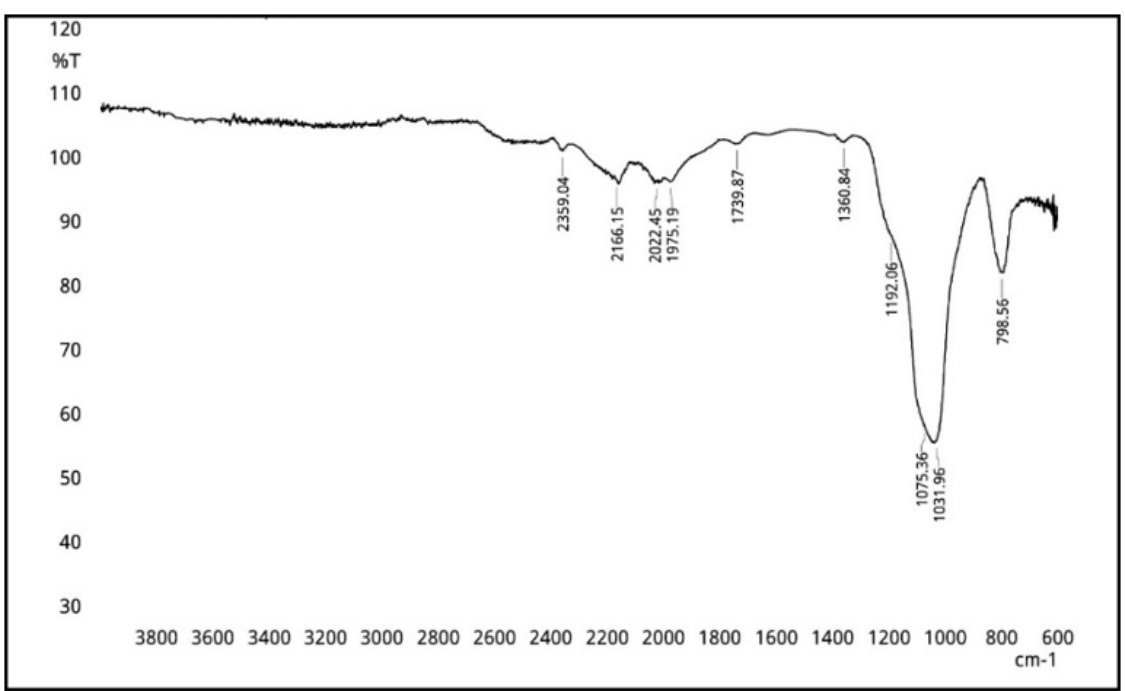

Figure 12: FTIR analysis of silica nanoparticles.

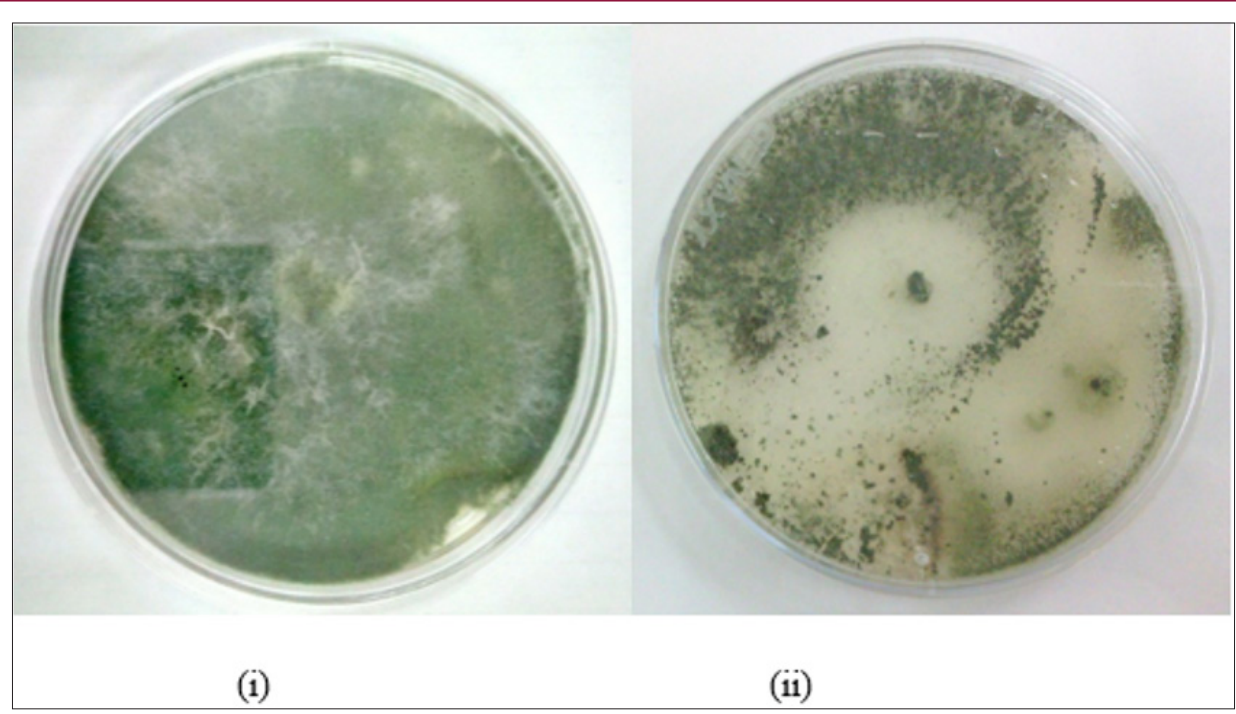

Figure 13: Growth of Trichoderma Harzianum in (i) control (ii) media containing silica nanoparticles.

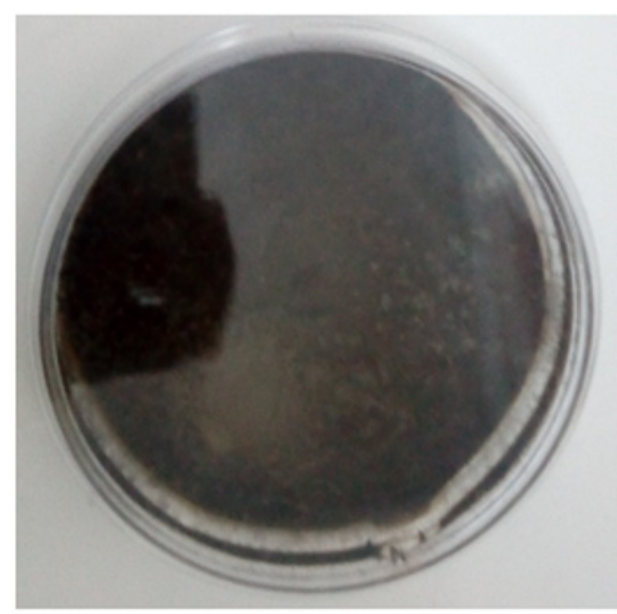

(i)

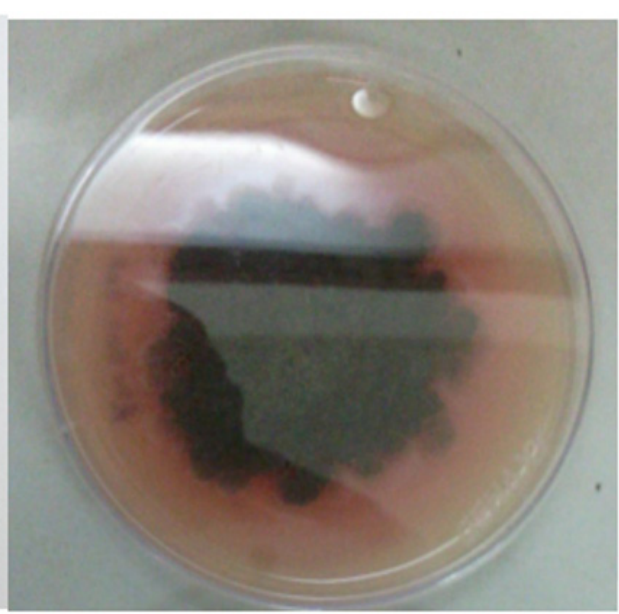

(ii)

Figure 14: Growth of Rhizoctonia Solani in (i) control (ii) media containing silica nanoparticles. 


\section{Conclusion}

We successfully prepared silica nanoparticles using sol-gel synthesis and peptization process. Characterization like DLS, UV spectroscopy, X-ray Diffraction, SEM was successfully performed. Presence of silica nanoparticle shows significant growth reduction of both type of fungus- trichoderma harzianum and rhizoctonia solani. This nanoparticle can be incorporated in various nanocoating for fungal growth reduction. These coatings can be used at various places like hospitals, toilets etc.

\section{Acknowledgement}

We thank Prof. D.K. Avasthi, Director of Amity Institute of Nanotechnology, Amity University, Noida, Uttar Pradesh, for his continuous guidance, motivation and providing all facilities. Our sincere thanks to Dr.B.K.Goswami, Dr.Neetu Singh and Archana Singh from Amity Centre for Biomedical \& Plant Disease Management for providing all kind of support for this project.

\section{References}

1. Ruchi Nandanwar, Purnima Singh, fozia zia Haque (2013) Mat Sci Res India Biol 10(1): 85-92.

2. LL Hench, JK West (1991) Chemical Review 90: 133.

3. P Kortesuo, M Ahola, S Karlsson, I Kangasniemi, J Kiesvaara, et al. (2000) Silica xerogel as an implantable carrier for controlled drug deliveryevaluation of drug distribution and tissue effects after implantation. Biomaterials 21(2): 193-198.

4. RA Cunaso, A Susha, F Cunaso (2001) Multilayered Titania, Silica, and Laponite Nanoparticle Coatings on Polystyrene Colloidal Templates and Resulting Inorganic Hollow Spheres. Chem Mater 13(2): 400-409.

\section{ISSN: 2574-1241}

DOI: $10.26717 / B J S T R .2018 .10 .001972$

Jaya Verma. Biomed J Sci \& Tech Res

\section{(c) (i) This work is licensed under Creative}

Submission Link: https://biomedres.us/submit-manuscript.php
5. K Han, ZH Zheo, Z Xiang, CL Wang (2007) Mater Lett 61: 368.

6. YS Han, GY Jeong, SY Lee, KH Meen (2009) Chem Mater 15: 1278.

7. HK Kammler, SE Pratsinis (2001) Flame Synthesis of Nanoparticles. Chem Eng Tech 24: 583.

8. JH Jahnson, AJ Mcfarlane, T Borrmann, J Moraes (2004) Current Appl Physics 4: 411.

9. W Stober, A Fink, E Bohn (1968) Controlled growth of monodisperse silica spheres in the micron size range. J Colloid Interface Sci 26(1): 6269.

10. GH Bogush, MA TRACY, CF Zukoski (1988) Preparation of Monodisperse Silica Particles: Control of Size and Mass Fraction. J Non Cryst Solids 104(1): 95-106.

11. P Sung Kyoo, B Ki Dok, K HeeTaik (2002) Preparation of silica nanoparticles: determination of the optimal synthesis conditions for small and uniform particles. Colloids and Surfaces A: Physicochemical and engineering Aspects 197(1-3): 7-17.

12.SR Ryu, M Tomozawa (2006) Fictive temperature measurement of amorphous $\mathrm{SiO}_{2}$ films by IR method. J Non Cryst Solids 352: 3929-3935.

13. B Gorji, MR Allahgholi Ghasri, R Fazaeli, N Niksirat (2012) Synthesis and Characterizations of Silica Nanoparticles by a New Sol-Gel Method. J Appl Chem Res 6(3): 22-26.

14. Manisha K, Panwar N (2012) Morpho Pathological Effects of Isolated Fungal Species on Human Population. Scientific reports 1: 521.

15. Srivastava OP, Lal B, Agrawal PK, Agarwal SC, Chandra B, et al. (1977) Mycotic keratitis due to Rhizoctonia sp. Sabouraudia 15(2): 125-131.

16. NM Kaore, AR Atul, MZ Khan, VK Ramnani (2012) A rare case of human mycosis by Rhizoctonia solani. case report 30(3): 361-363.

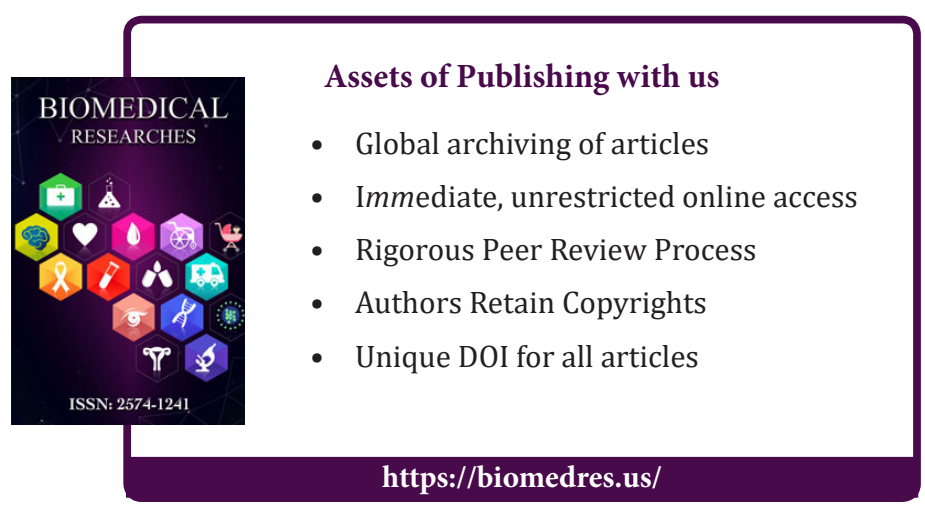

